Original papers

\title{
Dynamic modelling of the baseline temperatures for computation of the crop water stress index (CWSI) of a greenhouse cultivated lettuce crop
}

\author{
Olutobi Adeyemi ${ }^{\mathrm{a}}$, Ivan Grove ${ }^{\mathrm{a}}$, Sven Peets ${ }^{\mathrm{a}}$, Yuvraj Domun ${ }^{\mathrm{a}}$, Tomas Norton ${ }^{\mathrm{b}, *}$ \\ a Engineering Department, Harper Adams University, Newport, Shropshire TF10 8NB, United Kingdom \\ ${ }^{\mathbf{b}}$ M3-BIORES Research Group, Division of Animal and Human Health Engineering, Department of Biosystems, Katholieke Universiteit Leuven, Belgium
}

\section{A R T I C L E I N F O}

\section{Keywords:}

Sensing

Modelling

Crop canopy temperature

Crop water stress index

Irrigation scheduling

\begin{abstract}
A B S T R A C T
The crop water stress index (CWSI) has been shown to be a tool that could be used for non-contact and real-time monitoring of plant water status, which is a key requirement for the precision irrigation management of crops. However, its adoption for irrigation scheduling is limited because of the need to know the baseline temperatures which are required for its calculation. In this study, the canopy temperature of greenhouse cultivated lettuce plants which were maintained as either well-watered or non-transpiring was continuously monitored along with prevailing environmental conditions during a five week period. This data was applied in developing a dynamic model that can be used for predicting the baseline temperatures. Input variables for the dynamic model included air temperature, shortwave irradiance, and air vapour pressure deficit measured at a $10 \mathrm{~s}$ interval. During a follow up study, the dynamic model successfully predicted the baseline temperatures producing mean absolute errors (MAE) that varied between $0.17{ }^{\circ} \mathrm{C}$ and $0.29^{\circ} \mathrm{C}$, and root mean squared errors (RMSE) that varied between $0.21^{\circ} \mathrm{C}$ and $0.35^{\circ} \mathrm{C}$ when comparing model predictions with measured values. The model predicted baseline temperatures were applied in calculating an empirical CWSI for lettuce plants receiving one of two irrigation treatments. The empirical CWSI consistently differentiated between the irrigation treatments and was significantly correlated with the theoretical CWSI with correlation coefficient $(r)$ values greater than 0.9 . The dynamic model presented in this study requires easily measured input parameters for the prediction of the baseline temperatures. This eliminates the need to maintain artificial reference surfaces required in other empirical approaches for the CWSI calculation and also eliminates the need for computing the complex theoretical CWSI.
\end{abstract}

\section{Introduction}

Optimization of crop quality during protected crop cultivation requires finely tuned water management; here, protected crop cultivation refers to crops grown under fixed structures such as greenhouses and polytunnels. The improvement of crop quality is a major aim of protected crop cultivation in humid countries such as the UK (Monaghan et al., 2013). Imposing a certain degree of water stress in determined phenological periods has been found to improve crop quality in a number of crops including lettuce (Monaghan et al., 2017; Oh et al., 2010), strawberries (Weber et al., 2016), tomatoes (Kuscu et al., 2014; Shao et al., 2008). Monitoring tools that provide accurate information regarding plant water status would, therefore, be beneficial for scheduling and management of irrigation in protected crop cultivation (Adeyemi et al., 2017).

Plant canopy temperature $\left(T_{c}\right)$ has long been considered as an indicator of plant water status (Tanner, 1963) based on the cooling effect of the transpiration process (Jones and Schofield, 2008). Therefore, as a remote monitoring solution, infra-red thermometry offers the potential of acquiring the surface temperature of plant canopies from which plant water status can be inferred (Jones and Leinonen, 2003). $T_{c}$ is determined not only by the plant water status but also by prevailing environmental conditions including incoming shortwave irradiance, wind speed, air temperature and humidity (Jones et al., 1997).

To use $T_{c}$ as an indicator of plant water status, it must be normalized to account for the varying environmental conditions (Agam et al., $2013 \mathrm{~b}$ ). One of the most commonly used methods for normalizing $T_{c}$ as an indicator of plant water status is the crop water stress index (CWSI) originally proposed by Jackson et al. (1981); Idso et al. (1981) in which the measured crop canopy temperature $\left(T_{c}\right)$ is normalized using two baseline temperatures, both assumed to be achieved under the same environmental conditions as $T_{c}$; namely (a) the canopy temperature of a

\footnotetext{
* Corresponding author.

E-mail address: tomas.norton@kuleuven.be (T. Norton).
} 
well-watered crop $\left(T_{n w s}\right)$; referred to as the non-water-stressed baseline temperature, and (b) the temperature of a non-transpiring canopy $\left(T_{d r y}\right)$; referred to as the upper limit baseline temperature. Ideally, the CWSI ranges from 0 to 1 , where 0 represents a well-watered condition and 1 represents a non-transpiring, water-stressed condition, hence providing intuitive crop water status quantification as a simple tool for irrigation scheduling (King and Shellie, 2016).

Two forms of the CWSI are currently available. The first is the empirical CWSI, originally introduced by Idso et al. (1981). In their empirical approach to quantifying the CWSI, $T_{n w s}$ and $T_{d r y}$ were determined by developing a linear relationship for the canopy-air temperature difference and the vapour pressure deficit (VPD). It has however been shown that $T_{n w s}$ is crop growth stage dependent and also dependent on the agro climatic zone in which the crop is being grown (Jones, 1999). The stable weather conditions required for the application of the original approach to quantifying the CWSI is also seldom encountered in humid regions where weather conditions are highly variable in the short term (Maes and Steppe, 2012). Artificial wet and dry reference surfaces have been successfully applied to estimate $T_{n w s}$ and $T_{d r y}$ under the same environmental conditions as $T_{c}$ for the calculation of an empirical CWSI (Grant et al., 2007; Möller et al., 2007). These include the use of wet and dry filter papers, leaves sprayed with water and those covered with petroleum jelly, and plots maintained as well watered and water stressed. However, the required maintenance of these artificial surfaces limit their potential use for automation in a precision irrigation system including periods during which high frequency data acquisition is required (Maes and Steppe, 2012).

The use of theoretical equations of CWSI based on the energy balance model of Jackson et al. (1981) involves the combination of $T_{c}$ and meteorological measurements to compute the CWSI. This approach eliminates the need to acquire separate measurements of $T_{n w s}$ and $T_{d r y}$. It is however limited by the need to estimate net radiation and aerodynamic resistance, and also requires large model input parameters (Agam et al., 2013b). The energy balance model proposed by Jones (1999) requires less model input parameters and the baseline temperatures computed using the model have been demonstrated to show excellent agreement with the measured temperatures of artificial reference leaf surfaces under minimal wind conditions (Fuentes et al., 2012). It has further been demonstrated as producing a robust quantification of the CWSI and eliminates the need for artificial reference surfaces (Ben-Gal et al., 2009). However, the model requires ancillary measurement to reliably estimate equation parameters including the boundary layer resistance to heat and water vapor which limits the potential of its application in commercial crop production.

Baseline temperature prediction models which have limited data requirements and straightforward calculation will, therefore, enhance the adoption of the CWSI as a practical irrigation monitoring tool. Maes and Steppe (2012) noted that this could be realized through improvements in the prediction of the baseline temperatures employed in the empirical CWSI approach. Including air temperature, solar radiation, wind speed and VPD as predictors in multiple linear regression models (MLR) has been found to improve the predictions of the baseline temperatures (Payero and Irmak, 2006). King and Shellie (2016) also reported improved predictions of the baseline temperatures using an artificial neural network (ANN), with air temperature, solar radiation, wind speed and VPD applied as input variables. The plant response will typically vary over the growth season due to crop growth and various adaptation processes (Boonen et al., 2000). Dhillon et al. (2014) showed that baseline temperature prediction models for tree crops varied as the season progressed. Hedley et al. (2014) noted that adaptive monitoring systems which are able to account for the temporal variability in plant response and water requirements would improve the performance of irrigation management tools. The ANN and MLR approaches however fail to consider the time-varying nature of the plant systems as their model parameters are assumed to remain constant once identified.
Dynamic models provide a possible approach for accounting for the time-varying nature of the plant system in the prediction of the baseline temperatures. Dynamic models have been successfully applied in simplifying and modelling complex environmental and biological processes (Taylor et al., 2007; Young, 2006), predicting time-varying biological responses (Kirchsteiger et al., 2011; Quanten et al., 2006), and in many other irrigation decision support applications (Delgoda et al., 2016; Lozoya et al., 2016). To the best of our knowledge, a dynamic model has not ever been used to predict $T_{n w s}$ or $T_{d r y}$ for calculation of a CWSI. A dynamic model is particularly well suited for predicting $T_{n w s}$ and $T_{d r y}$ because the time varying nature of the system under study can be taken into account through and adaptive and online estimation of the model parameters. This means the model parameters are updated recursively using all new incoming data from the system. Predicting plant canopy temperature may involve an understanding of the timing of the opening and closing of the stomates (Al-Faraj et al., 2000). A dynamic model is however able to implicitly account for the stomatal response by the inclusion of the time delay associated with each model input parameter.

The objectives of this paper are to exhibit the potential of using a dynamic model to predict $T_{n w s}$ and $T_{d r y}$ (baseline temperatures) and demonstrate the applicability in calculating an empirical CWSI for a lettuce crop (Lactuca sativa) grown under greenhouse conditions. Performance of the dynamic model was evaluated by comparing the model predicted baseline temperatures with measured baseline temperatures. The calculated empirical CWSI values were also compared with theoretical CWSI values.

\section{Theoretical background}

\subsection{Empirical CWSI}

The empirical CWSI introduced by Idso et al. (1981) hereafter referred to as $\mathrm{CWSI}_{\mathrm{E}}$, is defined as

$\mathrm{CWSI}_{\mathrm{E}}=\frac{T_{C}-T_{n w s}}{T_{d r y}-T_{n w s}}$

where $T_{C}\left({ }^{\circ} \mathrm{C}\right)$ is the actual canopy surface temperature under given environmental conditions, $T_{d r y}\left({ }^{\circ} \mathrm{C}\right)$ is the upper limit for canopy temperature and equates to the temperature of a non-transpiring canopy such as would occur if the stomata were completely closed as a result of drought, while $T_{n w s}\left({ }^{\circ} \mathrm{C}\right)$ is the non-water stressed baseline representing the typical canopy of a well-watered crop transpiring at maximum rate.

Therefore, the temperature of a plant transpiring without soil water shortage can be assumed to represent $T_{n w s}$ and the temperature of a plant canopy from which all transpiration has been blocked, for example using petroleum jelly, can be assumed to represent $T_{d r y}$. This is similar to the methodology employed by Rojo et al. (2016) to calculate an empirical CWSI for grape and almond trees. In their study, $T_{n w s}$ and $T_{d r y}$ were measured using a well-watered tree and a simulated dry canopy.

\subsection{Theoretical CWSI}

The theoretical CWSI proposed by Jackson et al. (1981) hereafter referred to as $\mathrm{CWSI}_{\mathrm{T}}$ is calculated as

$\operatorname{CWSI}_{\mathrm{T}}=\frac{\left(T_{c}-T_{a}\right)-\left(T_{c}-T_{a}\right)_{L L}}{\left(T_{c}-T_{a}\right)_{U L}-\left(T_{c}-T_{a}\right)_{L L}}$

where $T_{c}-T_{a}$ is the canopy-air temperature difference, $\left(T_{c}-T_{a}\right)_{L L}$ is the lower baseline representing a non-stressed canopy, transpiring at potential rate and $\left(T_{c}-T_{a}\right)_{U L}$ is the upper baseline representing a stressed, non-transpiring canopy. The lower and upper baselines are given as

$\left(T_{c}-T_{a}\right)_{U L}=\frac{r_{a} I_{c}}{\rho_{a} c_{p}} R_{n}$ 


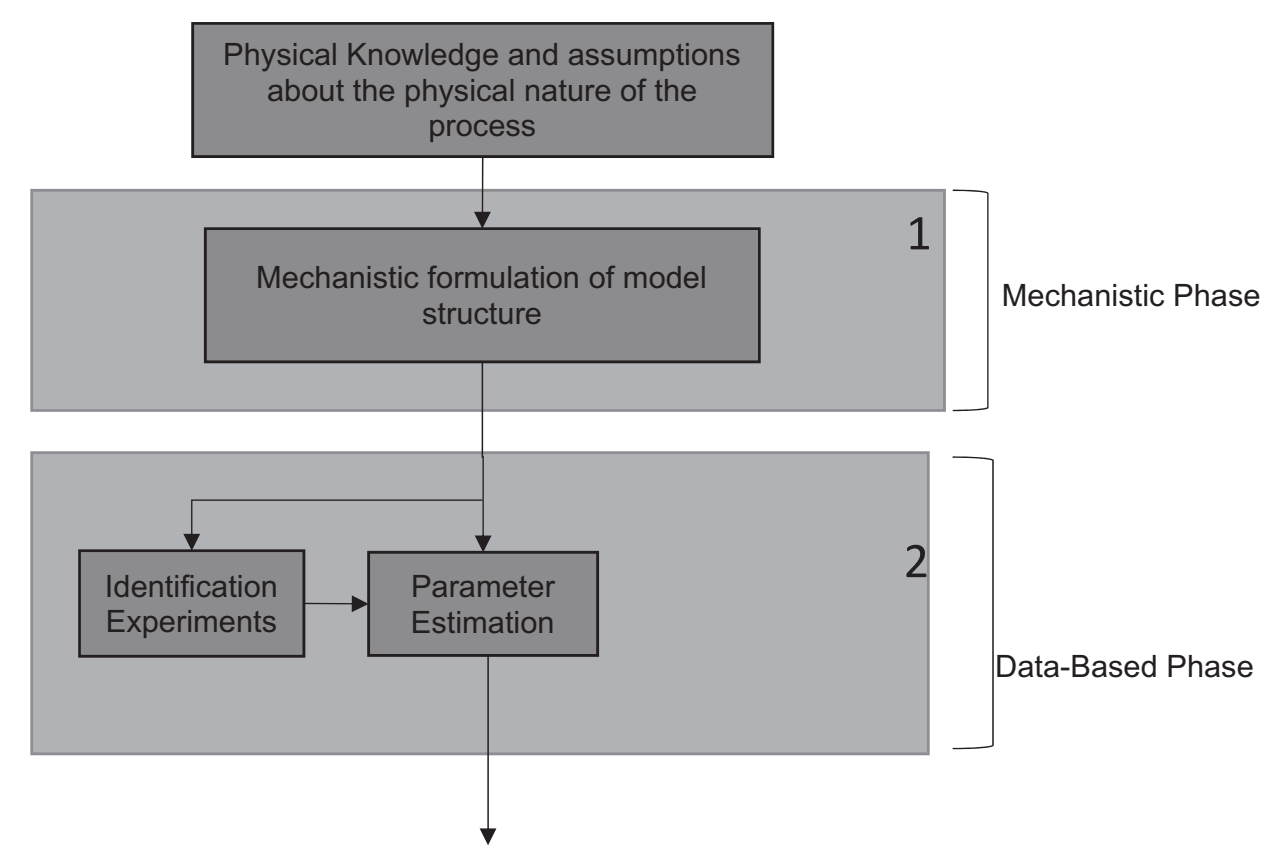

Fig. 1. The DBM modelling approach (Desta et al., 2004).

$\left(T_{c}-T_{a}\right)_{L L}=\frac{r_{a} I_{c}}{\rho_{a} c_{p}} \frac{\gamma\left(1+r_{c, p o t} / r_{a}\right)}{S+\gamma\left(1+r_{c, p o t} / r_{a}\right)} R_{n}-\frac{1}{s+\gamma\left(1+r_{c, p o t} / r_{a}\right)} \delta e$

where $r_{a}$ is the aerodynamic resistance $\left(\mathrm{sm}^{-1}\right), I_{c}$ is the interception coefficient, $\rho_{a}$ is the air density $\left(\mathrm{kgm}^{-3}\right), c_{p}$ is the specific heat capacity of air $\left(\mathrm{J} \mathrm{Kg}^{-1} \mathrm{~K}^{-1}\right), R_{n}$ is the net radiation $\left(\mathrm{Wm}^{-2}\right), s$ is the slope relating temperature with the saturation vapour pressure deficit $\left(\mathrm{PaK}^{-1}\right)$, $r_{c, p o t}$ is the canopy resistance at potential transpiration $\left(\mathrm{sm}^{-1}\right), \gamma$ is the psychometric constant $\left(\mathrm{kPaK}^{-1}\right)$, and $\delta e$ is the vapour pressure deficit $(\mathrm{kPa})$.

$\mathrm{CWSI}_{\mathrm{T}}$ has been shown to provide a robust quantification of the water status of various crops (Osroosh et al., 2015; Shaughnessy et al., 2012; Yuan et al., 2004). It can be estimated using the canopy temperature as measured by infrared radiometers and appropriate environmental measurements, including aerodynamic and canopy resistances.

\subsection{Dynamic response of the plant canopy temperature}

The plant canopy can be viewed as a natural dynamic input/output system. The inputs (prevailing meteorological conditions) applied to the system causes the system to respond with an output (canopy temperature) (Al-Faraj et al., 2000). Under minimal wind speed $\left(u, \mathrm{~ms}^{-1}\right.$ ) conditions, the dynamic response of the canopy temperature can be expressed in form of a first-order differential equation given as (Jones, 2014)

$$
\begin{aligned}
\frac{\mathrm{d} T_{c}(t)}{d t}+\left(\frac{\rho C_{p}}{\xi r_{H}}\right) T_{c}(t)= & \left(\frac{\rho C_{p}}{\xi r_{H}}\right) T_{a}\left(t-\tau_{a}\right)+\left(\frac{1}{\xi}\right) R_{n}\left(t-\tau_{r}\right) \\
& -\left(\frac{\rho C_{p}}{\xi \gamma\left(r_{C}+r_{H}\right.}\right)\left(e_{C}^{*}-e_{a}\right)\left(t-\tau_{v}\right)
\end{aligned}
$$

With $\rho^{*} C_{p}^{*} l^{*}=\xi$ where $t$ is the time (s), $\tau_{(a, r, v)}$ are the advective time delays ( $\mathrm{s}$ ) associated with the air temperature, radiation and vapour pressure deficit inputs respectively, $\rho$ is the air density $\left(\mathrm{Kgm}^{-3}\right), C_{p}$ is the heat capacity of air $\left(\mathrm{J} \mathrm{Kg}^{-1}{ }^{\circ} \mathrm{C}^{-1}\right), T_{c}$ is the canopy temperature $\left({ }^{\circ} \mathrm{C}\right)$, $T_{a}$ is the air temperature $\left({ }^{\circ} \mathrm{C}\right), e_{C}^{*}$ is the saturated vapour pressure at canopy temperature $(\mathrm{kPa}), e_{a}$ is the vapour pressure of air $(\mathrm{kPa}), r_{H}$ is the aerodynamic resistance $\left(\mathrm{sm}^{-1}\right), r_{C}$ is the canopy resistance $\left(\mathrm{sm}^{-1}\right), R_{n}$ is the net radiation $\left(\mathrm{Wm}^{-2}\right)$ and $\gamma$ is the psychrometric constant $(\mathrm{Pa}$ ${ }^{\circ} \mathrm{C}^{-1}$ ). 2000)

Using Laplace transform, Eq. (5) can be rewritten as (Al-Faraj et al.,

$$
(s+a) T_{c}(t)=a T_{a}\left(t-\tau_{a}\right)+b R_{n}\left(t-\tau_{r}\right)-c\left(e_{c}^{*}-e_{a}\right)\left(t-\tau_{v}\right)
$$

where

$$
\begin{aligned}
& s=d / d t \text { is the time derivative operator } \\
& a=\left[\rho C_{p}\right] /\left[\xi r_{H}\right]\left(\mathrm{s}^{-1}\right) \\
& b=\xi^{-1}\left(\mathrm{~m}^{2 \circ} \mathrm{CW}^{-1} \mathrm{~S}^{-1}\right) \\
& c=\left[\rho C_{p}\right] /\left[\xi \gamma\left(r_{c}+r_{H}\right)\right]\left({ }^{\circ} \mathrm{CPa}^{-1} \mathrm{~S}^{-1}\right)
\end{aligned}
$$

The net radiation flux $\left(R_{n}\right)$ absorbed by the crop can be systematically assumed to be equal to the net radiation measured above the crop, thus neglecting the radiation exchanged below the canopy and the ground. Thus, net radiation above the canopy is almost equal to the total shortwave irradiance $R_{s w}\left(\mathrm{Wm}^{-2}\right)$ during the day (Cannavo et al., 2016).

The canopy-air vapor pressure difference is Eq. (6). can be expressed in terms of vapor pressure deficit of the ambient air as

$e_{c}^{*}-e_{a}=\left(e_{a}^{*}-e_{a}\right)+\Delta$

where $\Delta\left(\mathrm{kPa}^{\circ} \mathrm{C}^{-1}\right)$ is the slope of the curve relating the saturation vapor pressure to temperature which is assumed to be approximately constant over the range $T_{c}$ to $T_{a}$ (Jones, 2014).

Since $\Delta$ is a constant, Eq. (7) is expressed with respect to time as $\left(e_{a}^{*}-e_{a}\right)$ which is the VPD of the ambient air as a function of time.

Therefore, Eq. (5) can be expressed as a first order continuous time multiple-input-single-output (MISO) transfer function model

$T_{c}(t)=\frac{a}{s+a} T_{a}\left(t-\tau_{a}\right)+\frac{b}{s+a} R_{s w}\left(t-\tau_{r}\right)-\frac{c}{s+a} V P D\left(t-\tau_{v}\right)$

The dynamic model in Eq. (8) has the canopy temperature $\left(T_{c}\right)$ as the model output. The model inputs are the dynamic course of air temperature $\left(T_{a}\right)$, shortwave irradiance $\left(R_{s w}\right)$ and the air vapour pressure deficit (VPD). The physical meaningfully model parameters to be estimated are $a, b$ and $c$ which can be accomplished using a suitable system identification technique described in Section 2.4. The identified parameters will be unique to the well-watered and non-transpiring canopies, and will also drive the dynamic response of their temperatures to the prevailing meteorological conditions. 
Table 1

Model Identified for the different LAI intervals.

\begin{tabular}{|c|c|c|c|c|c|c|c|c|c|c|}
\hline \multirow[t]{2}{*}{ LAI interval } & \multicolumn{5}{|c|}{$T_{n w s}$} & \multicolumn{5}{|c|}{$T_{d r y}$} \\
\hline & $\mathrm{n}$ & $\mathrm{m}$ & $\tau_{a}$ & $\tau_{r}$ & $\tau_{v}$ & $\mathrm{n}$ & $\mathrm{m}$ & $\tau_{a}$ & $\tau_{r}$ & $\tau_{v}$ \\
\hline 0.8 or lower & 1 & 1 & 2 & 2 & 2 & 1 & 1 & 2 & 2 & 2 \\
\hline $0.8-1.6$ & 1 & 1 & 1 & 2 & 2 & 1 & 1 & 1 & 2 & 2 \\
\hline $1.6-2.5$ & 1 & 1 & 1 & 1 & 2 & 1 & 1 & 2 & 1 & 2 \\
\hline 2.5 or higher & 1 & 1 & 1 & 1 & 1 & 1 & 1 & 1 & 1 & 2 \\
\hline
\end{tabular}

\subsection{Data-based mechanistic modelling approach}

Data-based mechanistic (DBM) modelling is a dynamic modelling approach applicable to transfer function models (Young, 2006). It consists of two phases as illustrated in Fig. 1. In the mechanistic phase, a model structure is formulated based on the physical knowledge of the process under consideration. In the data-based phase, time-series input/ output data are exploited to estimate the physically meaningful model parameters and the advective time delay associated with each model input (Desta et al., 2004).

The DBM model can be formulated in the form of a MISO continuous-time transfer function written as

$y(t)=\frac{B_{1}(s)}{A(s)} u_{1}\left(t-\partial_{1}\right)+\cdots+\frac{B_{k}(s)}{A(s)} u_{k}\left(t-\partial_{k}\right)+\frac{1}{C(s)} e(t)$

In Eq. (9), $y(t)$ is the output which is $T_{c}$ in this study, $u_{k}$ are the set of $\mathrm{k}$ inputs into the system which are $T_{a}, R_{s w}$ and VPD in this study, $\partial_{k}$ are the advective time delays associated with each input and $e(t)$ is the noise signal considered as zero mean, white noise with Gaussian amplitude distribution and variance.

$A(s)$ and $B(s)$ are polynomials in the derivative operator $s=d / d t$ of the form

$A(s)=s^{n}+y_{1} s^{n-1}+\cdots y_{n-1} s+y_{n}$

$B(s)=x_{0} s^{m}+x_{1} s^{m-1}+\cdots x_{m-1} s+x_{m}$

where $x, y$ are model parameters to be estimated for the $A(s)$ and $B_{1}(s) \cdots B_{k}(s)$ polynomials. The model structure is denoted by the triad $[n, m, \partial]$ where $n$ represents the number of parameters in the $A(s)$ polynomial, $m$ represents the number of parameters in each $B(s)$ polynomial and $\partial$ is the time delay associated with each input. By comparing Eq. (8) with Eqs. (9)-(11), in the present study, the model parameters to be identified are $a, b, c, \mathrm{n}=1$ ( $a$ in the denominators of Eq. (8) and $\mathrm{m}=1$ for each input ( $a, b$, cin the numerators of Eq. (8). The time delays are $\tau_{a}, \tau_{r}$ and $\tau_{v}$.

The continuous time MISO transfer function model parameters and time delays are estimated from the experimental input/output timeseries data using the recursive refined instrumental variable algorithm for continuous time systems (RIVC) (Taylor et al., 2007). This algorithm has been applied and validated for many practical applications (Young and Garnier, 2006). The RIVC optimally filters the data which ensures the estimation is statistically efficient and also generates the filtered derivatives of the input and output signals. The model estimated using the RIVC approach has statistically optimum properties due to the iterative and adaptive mode of solution used by the algorithm (Youssef et al., 2011).

\section{Methodology}

Plant canopy temperature and meteorological data for lettuce plants cultivated under greenhouse conditions were collected for the development and testing of the dynamic model.

The lettuce crop was selected for our study because of its highly sensitive response to water stress. Irrigation is also widely optimized to
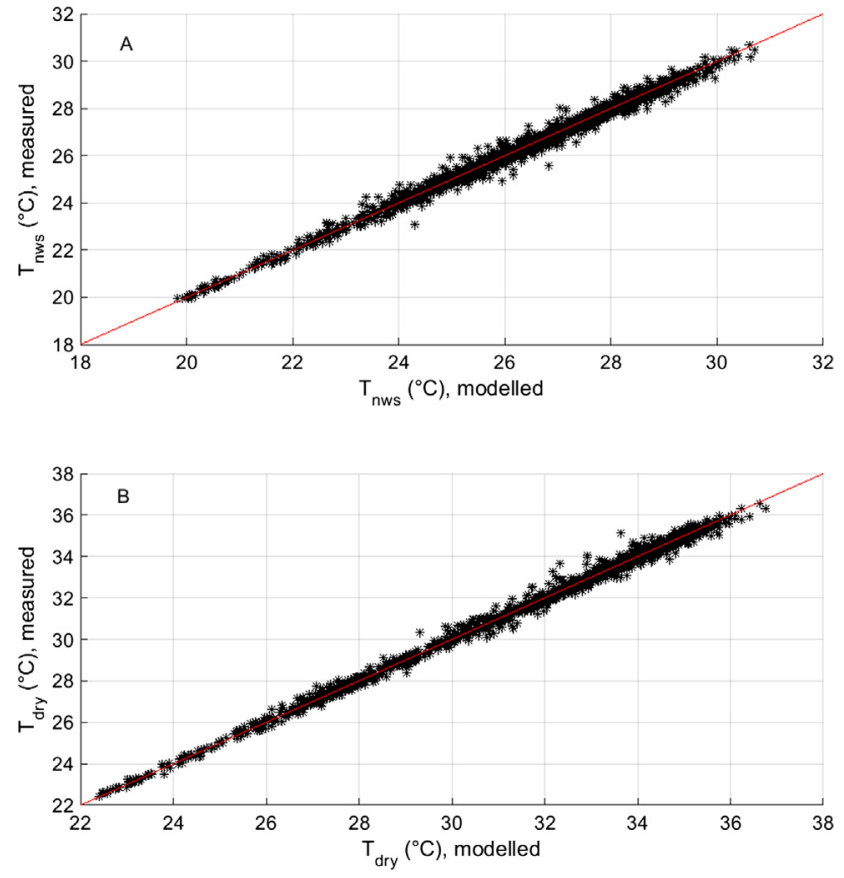

Fig. 2. Comparison between the measured and modelled predicted baseline temperatures for the four model evaluation days (A) $T_{n w s}$ (B) $T_{d r y}$.

Table 2

Results of the comparison between the measured and model predicted baseline temperatures.

\begin{tabular}{lllll}
\hline \multirow{2}{*}{ LAI interval } & \multicolumn{3}{l}{$T_{n w s}$} & \multicolumn{2}{l}{$T_{d r y}$} \\
\cline { 2 - 5 } & RMSE $\left({ }^{\circ} \mathrm{C}\right)$ & $\operatorname{MAE}\left({ }^{\circ} \mathrm{C}\right)$ & RMSE $\left({ }^{\circ} \mathrm{C}\right)$ & $\operatorname{MAE}\left({ }^{\circ} \mathrm{C}\right)$ \\
\hline 0.8 or lower & 0.35 & 0.29 & 0.31 & 0.24 \\
$0.8-1.6$ & 0.23 & 0.18 & 0.25 & 0.20 \\
$1.6-2.5$ & 0.21 & 0.17 & 0.28 & 0.21 \\
2.5 or higher & 0.22 & 0.18 & 0.22 & 0.17 \\
\hline
\end{tabular}

enhance the post-harvest quality of the crop (Monaghan et al., 2017). Some previous studies have reported the canopy temperature as a useful indicator of the plant water status of the lettuce crop (Qiu et al., 2009; Story and Kacira, 2015).

\subsection{Plants and measurements}

The canopy temperature of randomly selected lettuce plants was continuously measured for two five week study periods.

At the start of the initial five week study, eight plants were maintained as well-watered by adding irrigation volumes to fully replace daily water loss through crop evapotranspiration $\left(\mathrm{ET}_{\mathrm{C}}\right)$. This set of plants were used for $T_{n w s}$ measurements. Petroleum jelly was applied on the leaves of eight other plants to completely inhibit transpiration, and this set of plants were used for $T_{d r y}$ measurements. Prior to the application of the petroleum jelly, these plants received irrigation volumes to fully replace $\mathrm{ET}_{\mathrm{C}}$ water loss. The plants selected for $T_{\text {dry }}$ measurements were replaced after three days with a new set of plants which had been receiving full irrigation volumes in order to ensure uniform development of the plant canopy.

During a follow up five week study with a new set of lettuce plants receiving irrigation volumes to fully replace water loss through $\mathrm{ET}_{\mathrm{C}}$, two days prior to the commencement of measurements, four replicate lettuce plants received one of two irrigation treatments supplying; $80 \%$ of $\mathrm{ET}_{\mathrm{C}}$ and $40 \%$ of $\mathrm{ET}_{\mathrm{C}}$. The treatments are hereafter referred to as $80 \mathrm{ET}$ 

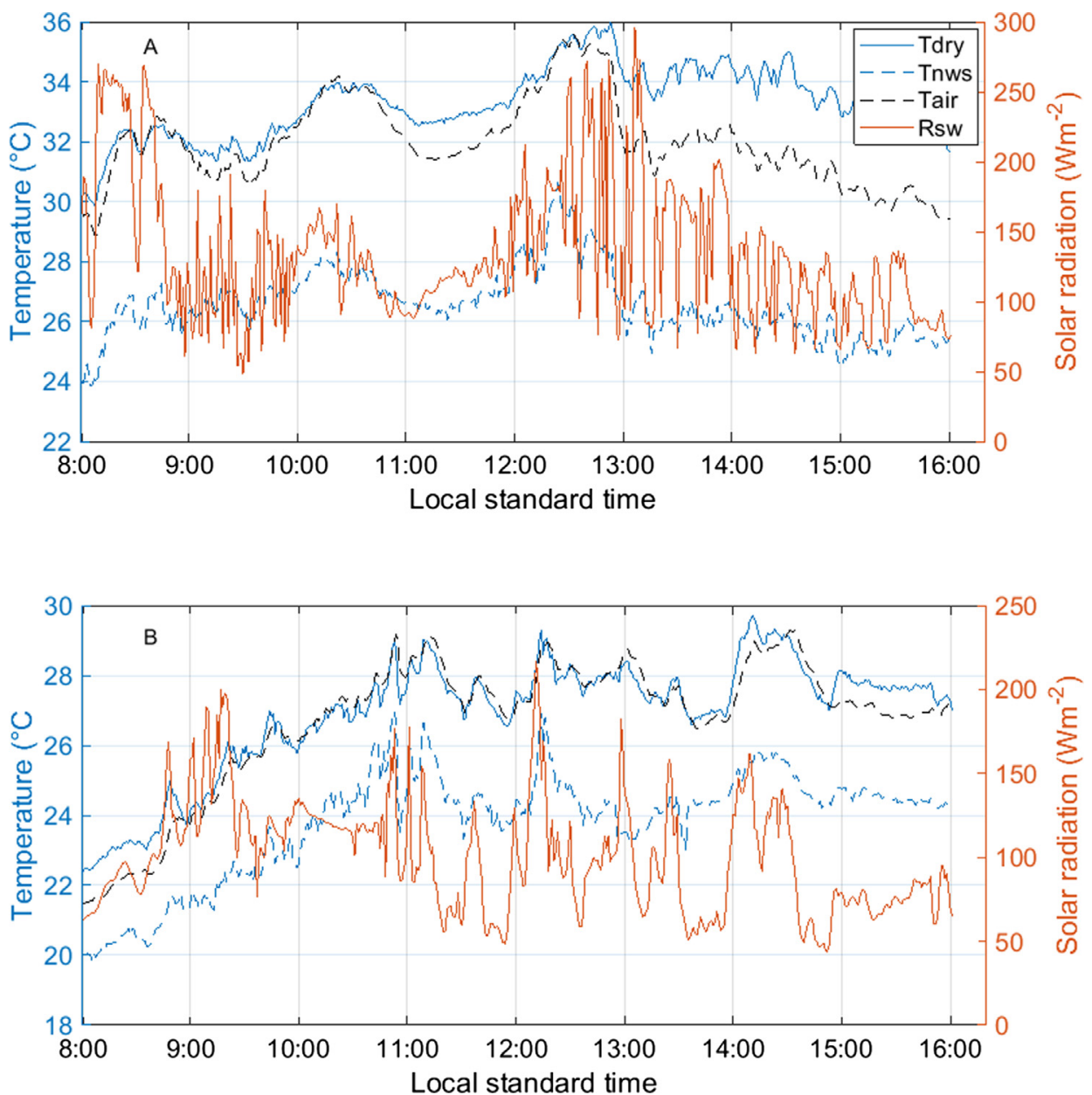

Fig. 3. The diurnal dynamics of the baseline temperatures $\left(T_{d r y}\right.$ and $\left.T_{n w s}\right)$ along with the incoming shortwave irradiance $\left(R_{s w}\right)$ and ambient air temperature $\left(T_{a i r}\right)$. (A) Sunny day (B) Cloudy day.
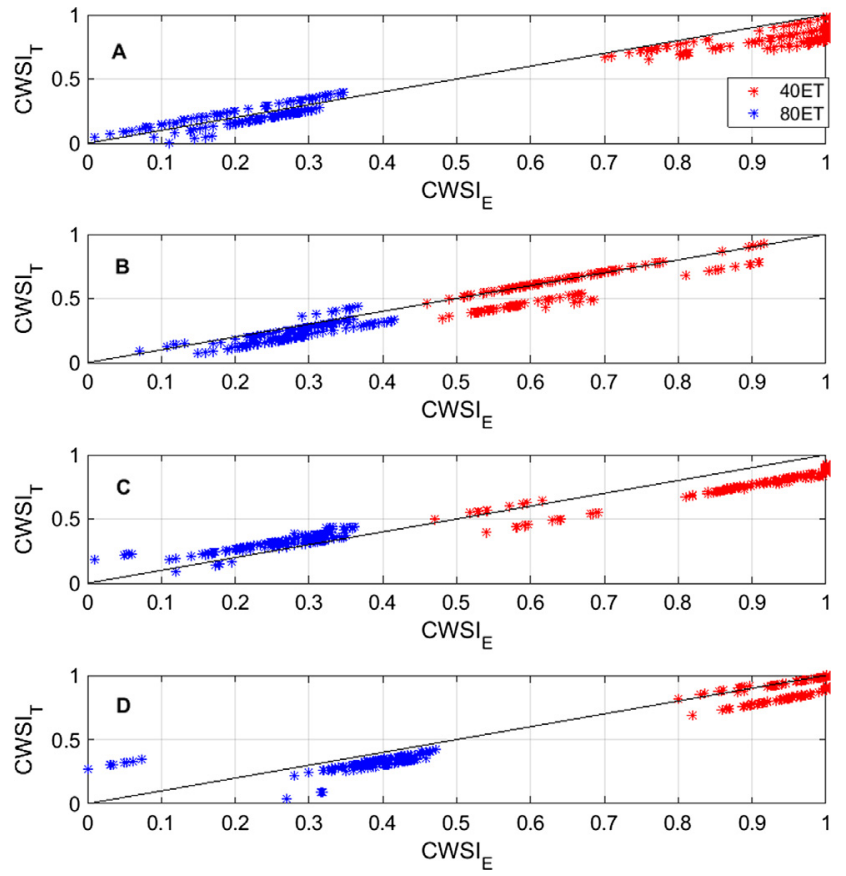

Fig. 4. Comparison of $\mathrm{CWSI}_{\mathrm{E}}$ and $\mathrm{CWSI}_{\mathrm{T}}$ during the model evaluation period (A) D1 (B) D2 (C) D3 (D) D4.
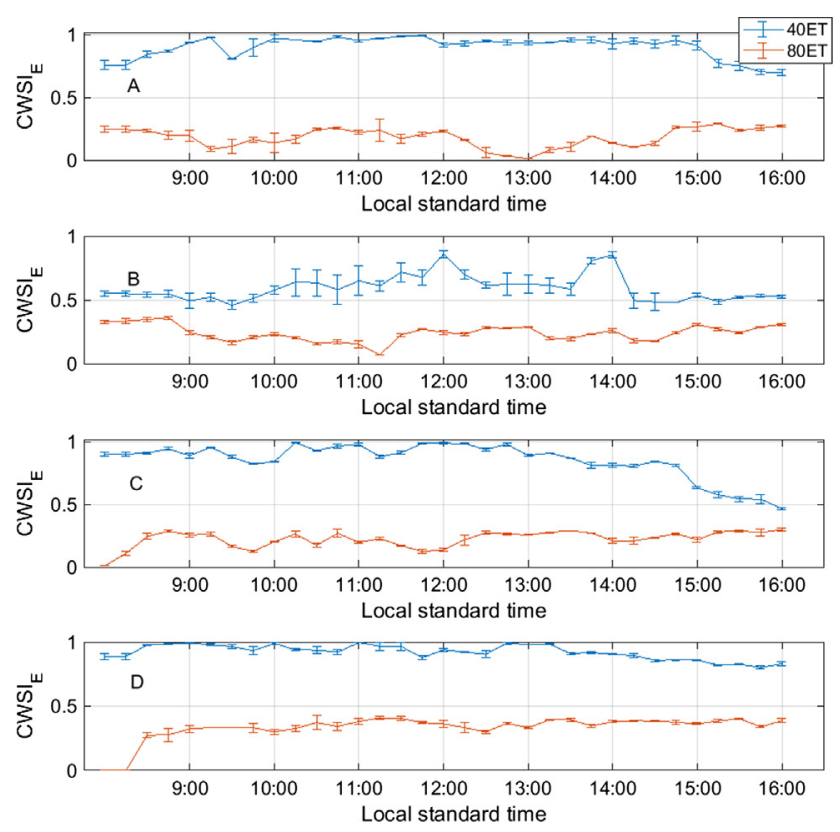

Fig. 5. Diurnal dynamics of $\mathrm{CWSI}_{\mathrm{E}}$ during the model evaluation period (A) D1 (B) D2 (C) D3 (D) D4. 

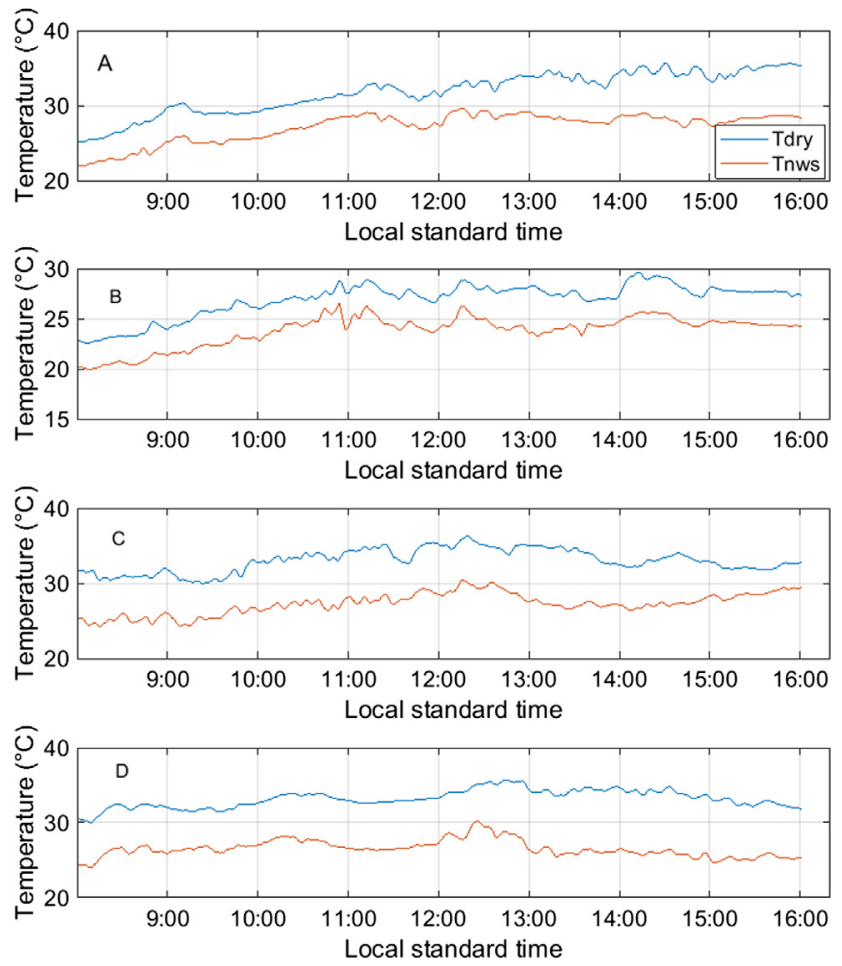

Fig. 6. Diurnal dynamics of the baseline temperatures $\left(T_{d r y}\right.$ and $\left.T_{n w s}\right)$ during the model evaluation period (A) D1 (B) D2 (C) D3 (D) D4.

and 40ET respectively. These sets of plants were used for $T_{c}$ measurements for the calculation of the CWSI. This methodology was applied in order to ensure uniform development of the plant canopy. A total of ten plants were also maintained as well-watered and stressed for assessing the model prediction of the baseline temperatures.

The canopy temperature of each of the plants was continuously measured using Pyro NFC infrared (IR) sensors (Calex Electronic Limited, Bedfordshire, UK). The IR sensors operate at a spectral range of $8-14 \mu \mathrm{m}$. The sensors were positioned approximately $30-50 \mathrm{~cm}$ above the plant canopy and pointed in a nadir direction. The temperature sensing area was approximately $3-5 \mathrm{~cm}$ to ensure only the plant canopy was in the view of the IR sensors. Readings from the IR sensors were recorded every $10 \mathrm{~s}$.

Environmental variables measured at plant canopy level included ambient air temperature and relative humidity using a temperature and humidity probe (Model EE08, E + E Elektronik, Engerwitzdorf, Austria), and shortwave irradiance using a pyranometer sensor (Model SP-110, Apogee Instruments, Logan, Utah, USA). Wind speed was measured using a hot wire anemometer (Model AM - 4202, Lutron Electronics, London, UK) installed $10 \mathrm{~cm}$ above the crop canopy. The VPD was calculated using temperature and relative humidity data following the equations outlined in Allen et al. (1998). Readings from the sensors were recorded every $10 \mathrm{~s}$. All sensors were factory calibrated by their respective manufacturers.

Data from all the sensors were collected and stored using a CR1000 data acquisition system (Campbell Scientific, Logan, Utah, USA).

The leaf area index (LAI) values for the plants used for IR measurement were assessed using digital images captured with a mobile phone camera. The LAI values were then extracted from the digital images using the Easy leaf area software (Department of Plant Sciences, University of California). During the initial study period, leaf area measurement was conducted on six random plants every three days. The measurements were conducted prior to the application of petroleum jelly on the $T_{d r y}$ plants. During the follow up study leaf area measurement was conducted on six random plants, prior to the initiation of irrigation treatments.

\subsection{Dynamic model development for the baseline temperatures}

The DBM modelling approach was applied in developing the dynamic model of the baseline temperatures. This was achieved using all incoming time-series measurements of $T_{n w s}, T_{d r y}$ and environmental variables recorded during the initial five week period, resulting in an approximate total of 302, 000 data points for each measured variable. The parameter estimation was constrained to a first-order model following Eq. (8), and the model parameters and the time delay associated with each input were identified using the recursive RIVC algorithm.

\subsection{CWSI calculations}

The CWSI proposed by Idso et al. (1981) was intended as a tool for detecting the water status of plants around noon which corresponds to the period of peak plant transpiration. However, an extended period of between 8:00 and 16:00 $\mathrm{h}$ was explored during this study.

$\mathrm{CWSI}_{\mathrm{E}}$ was calculated for the 40ET and 80ET plants using their measured canopy temperature and the baseline temperatures predicted using the dynamic model. CWSI $_{\mathrm{T}}$ was also calculated for these plants using their measured canopy temperature and ancillary meteorological measurements. The aerodynamic resistance, $r_{a}$ was calculated following the equations of Thom and Oliver (1977) given as

$r_{a}=4.72\left\{\operatorname{In}\left[\frac{z-d}{z_{o}}\right]\right\}^{2} /(1+0.54 u)$

where $z$ is the measurement height $(m), d$ the displacement height (m), $z_{o}$ the roughness length $(m)$, and $u$ the windspeed $\left(\mathrm{ms}^{-1}\right)$. Values of $z_{0}$ and $d$ were derived from the plant height $h(\mathrm{~m})$ as $z_{o}=0.13 h$ and $d=0.67 \mathrm{~h}$. The canopy resistance at potential transpiration, $r_{c, p o t}$ was determined for each of the evaluation days by adjusting its value until the lowest CWSI value on that day was zero (González-Dugo et al., 2006).

The CWSI values were computed using 15 mins average values of the measured canopy temperature and environmental variables.

\subsection{Statistical analysis}

Model evaluation was carried out by comparing the $T_{n w s}$ and $T_{d r y}$ values predicted by the dynamic model and the measured values using several goodness-of-fit statistical indicators. These included the coefficient of determination $\left(R^{2}\right)$, the mean absolute error (MAE) and the root mean square error (RMSE). The coefficient of correlation $(r)$ was applied in comparing $\mathrm{CWSI}_{\mathrm{E}}$ with $\mathrm{CWSI}_{\mathrm{T}}$.

The MAE and RMSE were calculated as (Chai and Draxler, 2014).

MAE $=\frac{1}{n} \sum_{i=1}^{n}\left|P_{i}-O_{i}\right|$

$\operatorname{RMSE}=\left[\frac{\sum_{i=1}^{n}\left(P_{i}-O_{i}\right)^{2}}{n}\right]^{0.5}$

where $O_{i}$ and $P_{i}$ are measured and predicted value at time $i(i=1,2, \cdots \cdots n)$ respectively. $R^{2}$ values close to 1 indicate that the model explains well the variance of observations, and MAE and RMSE values close to zero indicate good model predictions (González et al., 2015). $r$ values close to 1 indicate a strong positive linear relationship between the compared variables.

\section{Results and discussion}

The recursive parameter identification for the development of the dynamic model was conducted using all incoming time-series of data collected during the initial five week study period. Data from four selected days during the follow up study, however, seem to be sufficient to conduct the model evaluation as this data shows a contrast in the 
prevailing environmental conditions (Appendix A) and crop growth stage (Appendix B). These days are hereafter referred to as D1, D2, D3 and D4 respectively.

\subsection{Dynamic modelling of the baseline temperatures}

The measured canopy temperatures of each of the plants maintained as either $T_{n w s}$ or $T_{d r y}$ were usually within $1{ }^{\circ} \mathrm{C}$ of each other. The average coefficient of variance was $1.8 \%$ for $T_{n w s}$ measurements and $2 \%$ for $T_{d r y}$ measurements. The average measured canopy temperature of the plants in each baseline temperature group was therefore applied in recursive parameter identification.

The dynamics of $T_{n w s}$ and $T_{d r y}$ were consistently described by a first order model as indicated in the transfer function model in Eq. (8). The standard errors associated with the recursive parameter estimates ranged from $4 \%$ to $10 \%$. The model residuals also had a zero mean with a standard deviation less than $\pm 1{ }^{\circ} \mathrm{C}$. These low parameter standard errors and residuals give evidence in favour of the first order model. It was however observed that the recursively identified model parameters and the time delay associated with the model inputs varied temporally over the plant growth cycle. For this reason, the LAI was used to divide the models into four intervals as shown in Table 1. The intervals include LAI values less than $0.8,0.8-1.6,1.6-2.5$ and above 2.5 . For the division, it is easy to change the LAI into other time units such as days after planting. The LAI evolution over the study period and identified model parameters are presented in Appendix C.

Taking plant growth into account when predicting baseline temperatures would greatly reduce the errors associated with the prediction as a result of the time-varying nature of the plant system. Payero and Irmak (2006) noted that plant growth affects the crop aerodynamic resistance, surface albedo and canopy resistance which affects the canopy temperature response and hence induces a change in established model parameters. The accuracy of regression models developed by the authors for predicting baseline temperatures for corn and soybean was greatly improved when they accounted for the evolution of the plant height.

\subsection{Baseline temperature prediction}

The comparisons between the model predicted and measured baseline temperatures are presented in Fig. 2. The data points in Fig. 2 are selected from D1 to D4 which corresponds to a day in each of the four LAI intervals used to divide the models (Appendix B). It is seen that the predicted $T_{n w s}$ are highly correlated with the measured $T_{n w s}$ values $\left(R^{2}=0.92\right)$. The predicted $T_{d r y}$ values are also highly correlated with the measured $T_{d r y}$ values $\left(R^{2}=0.95\right)$. Summary statistics on the comparison between the measured and model predicted baseline temperatures are also presented in Table 2.

Table 2 shows the model performs with reasonable accuracy in each LAI interval, recording low MAE and RMSE values. This suggests that the dynamic model can account for the time-varying response of the plant system and its influence on the canopy temperature response.

The dynamic response of the measured baseline temperatures along with prevailing shortwave irradiance and ambient air temperature for a sunny and cloudy day, are presented in Fig. 3. $T_{d r y}$ values are consistently higher than $T_{n w s}$ values which in turn maintain values lower than the ambient air temperature. It can also be seen that the fluctuations in the baseline temperature values closely follow the fluctuations in the incoming solar radiation. This is in agreement with results presented by Agam et al. (2013a). The importance of considering the diurnal dynamics of the baseline temperatures was highlighted in a study by Payero and Irmak (2006). In their study, significant diurnal variations as high as $5{ }^{\circ} \mathrm{C}$ was recorded for the baseline canopy and air temperature difference measured on corn and soybean crops. They attributed these variations to diurnal variations in the incoming solar radiation. They concluded that accounting for these diurnal variations and its effect on the canopy temperature dynamics will result in more accurate and realistic baseline temperature predictions. The empirical CWSI approach proposed by Idso et al. (1981) assumes the baseline temperatures are constant often leading to erroneous values during cloudy periods. Agam et al. (2013a) has shown that neglecting the influence of the prevailing environment on the baseline temperatures leads to a severe underestimation of CWSI values for stressed olive trees during periods of abrupt changes in radiation intensity.

It should be noted that the DBM modelling technique constitutes a data-driven approach in which the dynamic response of the baseline temperatures is parametrized for the specific ranges of environmental and crop conditions encountered during model development, and therefore the models are only applicable to the specific crop and environment for which they are developed. The methodology can, however, be adapted to any other location and crop grown under greenhouse conditions.

The high speed of the prevailing wind under field conditions results in turbulent and atmospheric and canopy exchanges which in turn alters the canopy energy balance. Hence, it may be important to consider the influence of the prevailing wind when developing dynamic models to estimate baseline temperatures for field grown crops.

\subsection{Comparison of the empirical and theoretical CWSI}

A comparison of the $\mathrm{CWSI}_{\mathrm{E}}$ and $\mathrm{CWSI}_{\mathrm{T}}$ values calculated during the four model evaluation days for the 40ET and 80ET plants is presented in Fig. 4. Both CWSI approaches are able to clearly separate the water status of the plants which explains the gaps in the plots. The CWSI values are significantly correlated $(\mathrm{p}<0.01)$ during all days with $r$ values greater than 0.9 . These high correlation values are demonstrated during all crop growth stages in form of the LAI evolution.

The empirical CWSI approach demonstrated in this paper requires easily measured meteorological variables and crop canopy temperature for its computation. The high correlation between the empirical CWSI and the widely validated theoretical CWSI further suggests it can be deployed as part of an irrigation monitoring tool. This will eliminate the need for the computation of the crop canopy and aerodynamic resistance which is required for the computation of the theoretical CWSI. It also eliminates the need to physically maintain dry and wet reference surfaces which are required for the baseline temperature computation in other empirical CWSI approaches.

\subsection{Daily dynamics of the crop water stress index}

The diurnal dynamics $\mathrm{CWSI}_{\mathrm{E}}$ calculated for the 40ET and 80ET plants were well differentiated during the four model evaluation days as shown in Fig. 5. The CWSI recorded for the 80ET crops ranged between 0.1 and 0.4 while those of the 40ET plants consistently approached values ranging from 0.8 to 1 at noon which coincides with the period of maximum atmospheric evaporative demand. The dynamics of the modelled baseline temperatures are also presented in Fig. 6 .

Agam et al. (2013b) suggested that the diurnal course of CWSI of well-watered plants will maintain a relatively constant level while that of stressed plants will increase until early afternoon and decrease after that, following the dynamics of evaporative demand. Indeed the diurnal course of $\mathrm{CWSI}_{\mathrm{E}}$ calculated for both 80ET and 40ET plants followed these patterns as shown in Fig. 5. The cloudless conditions that are required for the application of the original empirical CWSI approach may not occur often enough during noon in humid climates such as UK (Jones, 1999). The ability of the empirical CWSI approach proposed in this paper to depict the plant water status of lettuce over an extended diurnal period should, however, make its application in practice more flexible. This is because the baseline temperature values applied in its calculation are predicted as a function of the prevailing environment, limiting the underestimation of CWSI of stressed plants during cloudy periods as shown by Agam et al. (2013a). Furthermore, the results 
indicate that the CWSI calculated during diurnal periods different from the solar noon separates the water status of the stressed and well-watered plants, which will be particularly attractive for applications where there is a rapid change in the plants water status due to limited container volume or substrate water holding capacity.

It is however noted that while the empirical CWSI described in this paper can provide a useful indication of the need for irrigation, it is unable to estimate the amount of irrigation water that is needed. As such, this tool should be complemented with soil moisture measurements or estimations of $\mathrm{ET}_{\mathrm{C}}$ in order to implement a robust irrigation decision support system.

\section{Conclusions}

In this paper, the feasibility of using a dynamic model to predict the baseline temperatures needed to calculate an empirical CWSI was demonstrated for the lettuce crop cultivated in a greenhouse. The dynamic response of the baseline temperatures was modelled as a function of shortwave irradiance, air temperature and VPD, and parameters of the model varied in response to crop growth. The empirical CWSI values computed using the dynamic model predicted baseline temperatures were significantly correlated with theoretical CWSI values at all crop growth stages and successfully differentiated between two levels of irrigation treatment for the lettuce crop.

The dynamic modelling approach adopted in this study for predicting the baseline temperatures should enhance the application of the CWSI method for irrigation scheduling. It requires easily measured meteorological variables as input parameters, and it is able to account for the diurnal fluctuations in these variables in the baseline temperature prediction. It can also be applied in computing the CWSI over an extended diurnal period making its application more flexible. The requirement for the calculation of the aerodynamic resistances needed in the theoretical CWSI computation is eliminated. The need to maintain artificial reference surfaces applicable in other empirical CWSI approaches is also eliminated. The implementation of this model in a commercial greenhouse and model development for other high-value crops will be the focus of future research.

The authors wish to acknowledge John Oldacre foundation for funding this research project.

\section{Appendix A. Climatic conditions during model evaluation}

See Figs. A1-A4.
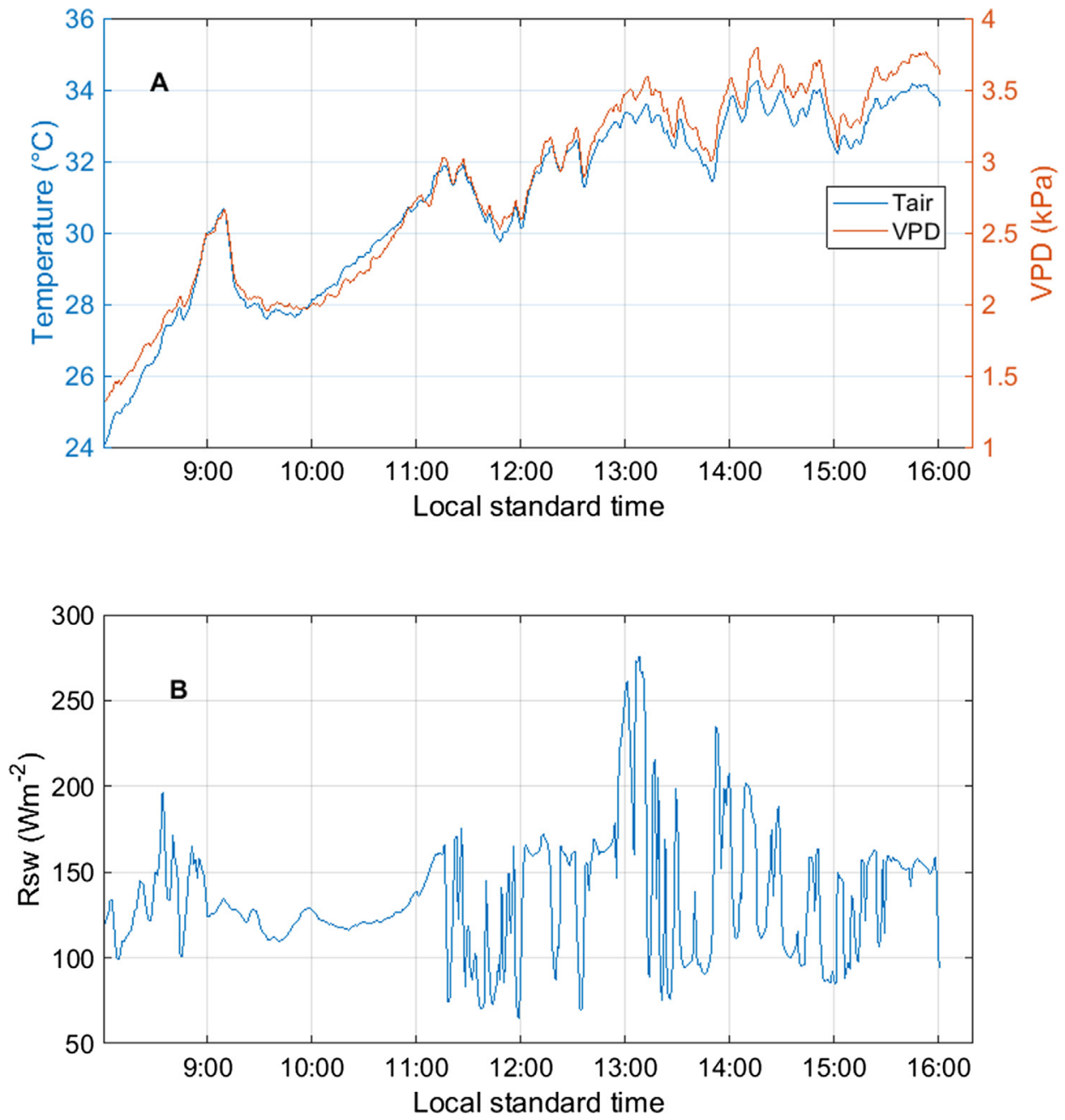

Fig. A1. Climatic conditions during D1 (A) $T_{a i r}$ (Air temperature) and VPD (B) $R_{s w}$ (Incoming shortwave irradiance). 

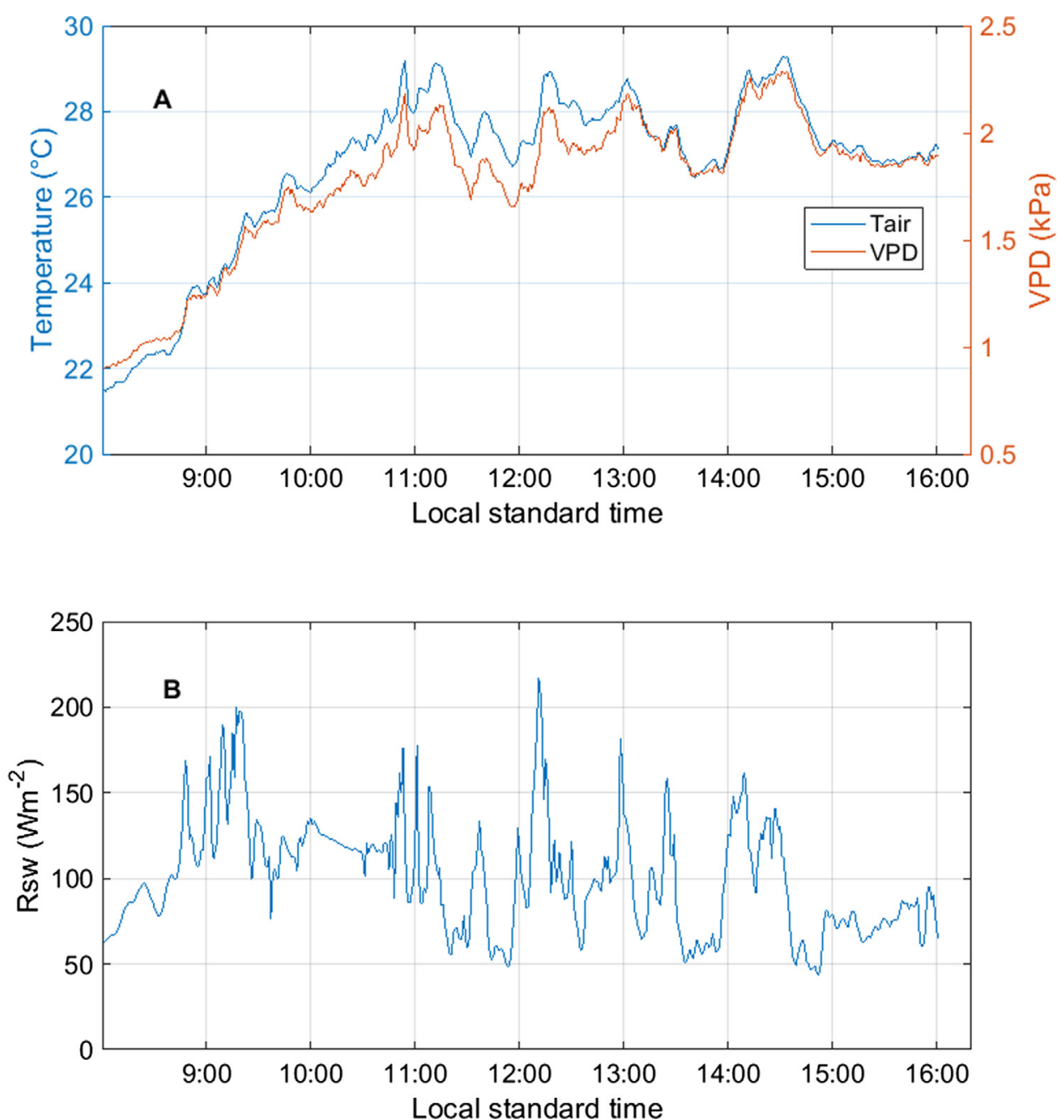

Fig. A2. Climatic conditions during D2 (A) $T_{a i r}$ (Air temperature) and VPD (B) $R_{s w}$ (Incoming shortwave irradiance). 

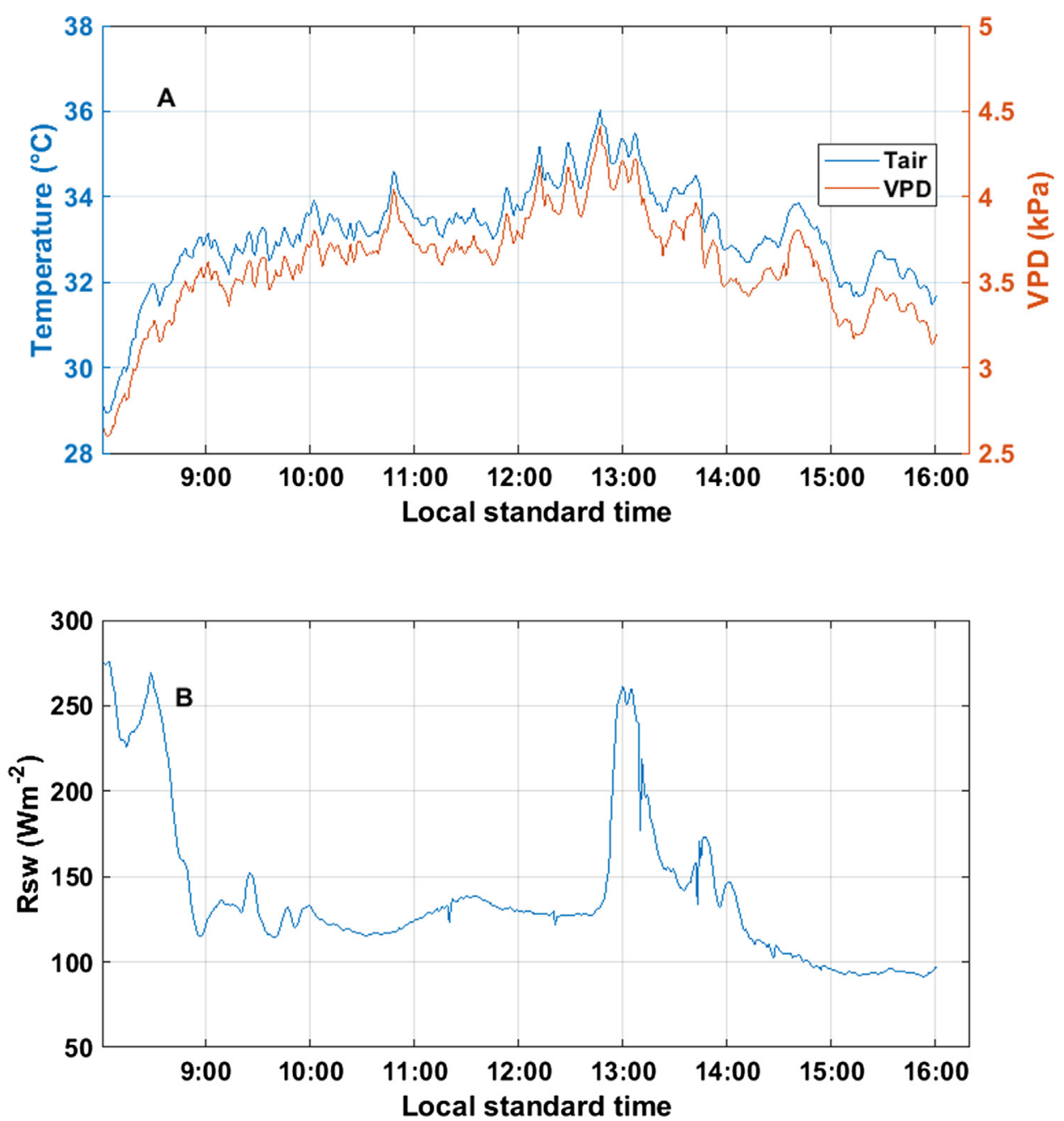

Fig. A3. Climatic conditions during D3 (A) $T_{\text {air }}$ (Air temperature) and VPD (B) $R_{s w}$ (Incoming shortwave irradiance). 

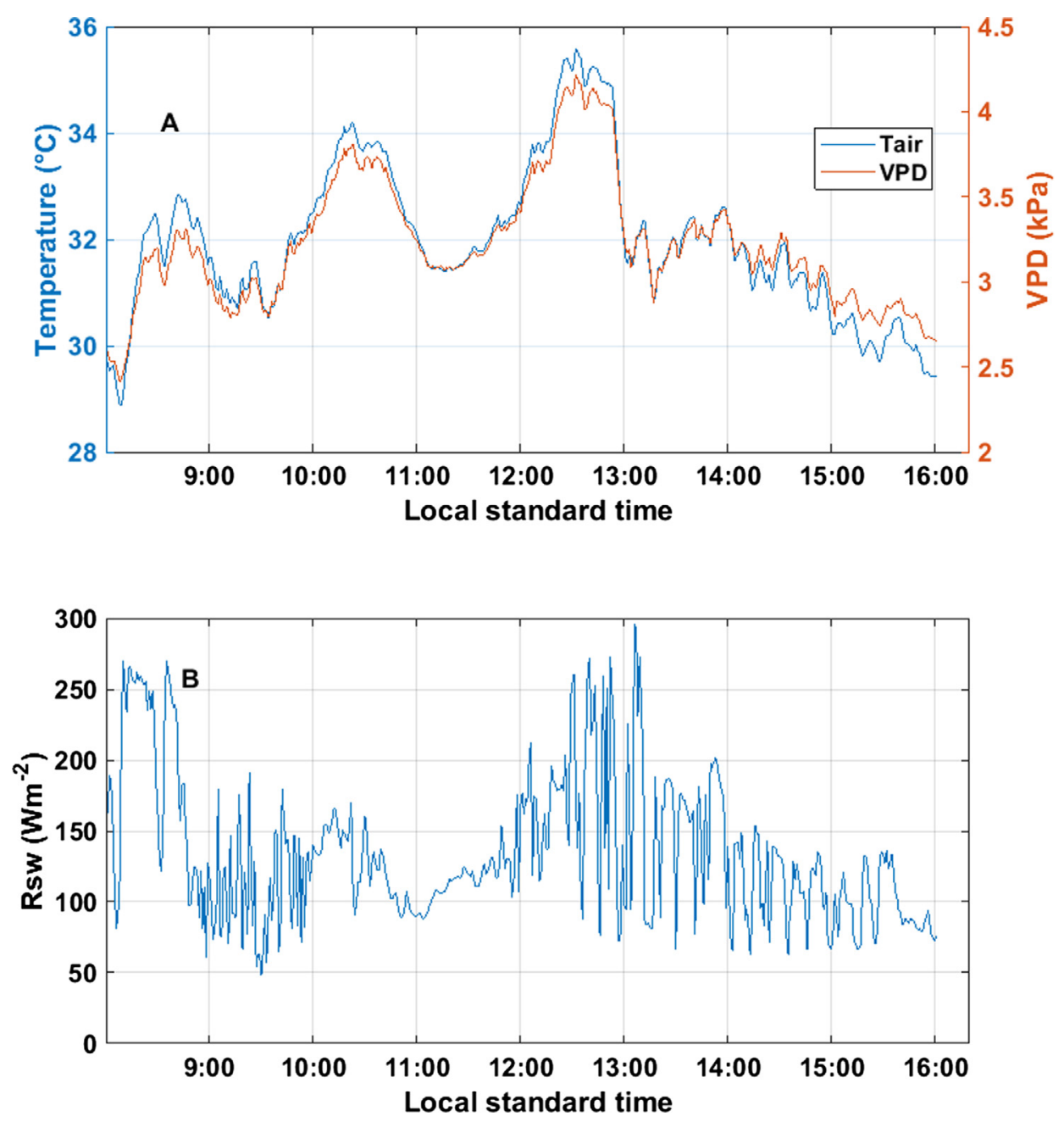

Fig. A4. Climatic conditions during D4 (A) $T_{a i r}$ (Air temperature) and VPD (B) $R_{s w}$ (Incoming shortwave irradiance).

Appendix B. Crop growth stage during the model evaluation days

See Table B1.

Table B1

LAI values (standard deviations in brackets) during the model evaluation days.

\begin{tabular}{lll}
\hline LAI value & LAI interval & Model evaluation day \\
\hline $0.6(0.03)$ & 0.8 or lower & D1 \\
$1.3(0.05)$ & $0.8-1.6$ & D2 \\
$2.2(0.15)$ & $1.6-2.5$ & D3 \\
$4.2(0.11)$ & 2.5 or higher & D4 \\
\hline
\end{tabular}




\section{Appendix C. Model parameters as a function of LAI evolution}

See Fig. C1 and Table C1.

Table C1

Model parameter estimation (standard errors in brackets) at different LAI intervals.

\begin{tabular}{|c|c|c|c|c|}
\hline \multirow[t]{2}{*}{ Baseline temperature } & \multicolumn{3}{|c|}{ Parameter estimates } & \multirow[t]{2}{*}{ LAI interval } \\
\hline & $\mathrm{a}$ & $\mathrm{b}$ & $\mathrm{c}$ & \\
\hline$T_{n w s}$ & $0.0043(0.0003)$ & $0.0018(0.0002)$ & $0.0060(0.0004)$ & 0.8 or lower \\
\hline$T_{n w s}$ & $0.0055(0.0004)$ & $0.0032(0.0003)$ & $0.0094(0.0003)$ & 0.8 to 1.6 \\
\hline$T_{n w s}$ & $0.0058(0.0002)$ & $0.0037(0.0005)$ & $0.0098(0.0011)$ & 1.6 to 2.5 \\
\hline$T_{n w s}$ & $0.0049(0.0003)$ & $0.0040(0.0005)$ & $0.0087(0.0002)$ & 2.5 or higher \\
\hline$T_{d r y}$ & $0.0022(0.0004)$ & $0.0013(0.0001)$ & $0.0028(0.0003)$ & 0.8 or lower \\
\hline$T_{d r y}$ & $0.0032(0.0007)$ & $0.0025(0.0002)$ & $0.0033(0.0002)$ & $0.8-1.6$ \\
\hline$T_{d r y}$ & $0.0037(0.0001)$ & $0.0031(0.0004)$ & $0.0038(0.0003)$ & $1.6-2.5$ \\
\hline$T_{d r y}$ & $0.0025(0.0002)$ & $0.0028(0.0001)$ & $0.0035(0.0001)$ & 2.5 or higher \\
\hline
\end{tabular}

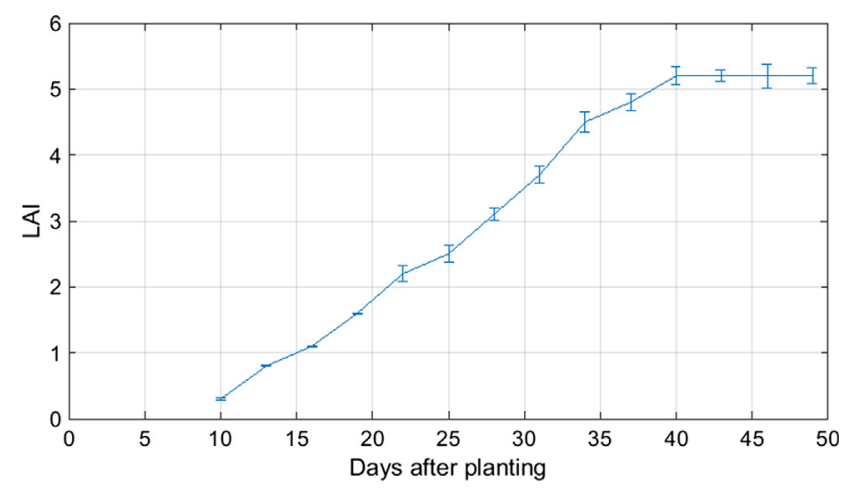

Fig. C1. LAI evolution during the study period.

\section{References}

Adeyemi, O., Grove, I., Peets, S., Norton, T., 2017. Advanced monitoring and management systems for improving sustainability in precision irrigation. Sustainability 9 , 1-29. https://doi.org/10.3390/su9030353.

Agam, N., Cohen, Y., Alchanatis, V., Ben-Gal, A., 2013a. How sensitive is the CWSI to changes in solar radiation? Int. J. Remote Sens. 34, 6109-6120. https://doi.org/10. 1080/01431161.2013.793873.

Agam, N., Cohen, Y., Berni, J.A.J., Alchanatis, V., Kool, D., Dag, A., Yermiyahu, U., BenGal, A., 2013b. An insight to the performance of crop water stress index for olive trees. Agric. Water Manage. 118, 79-86. https://doi.org/10.1016/j.agwat.2012.12. 004.

Al-Faraj, A., Meyer, G.E., Schade, G.R., Horst, G.L., 2000. Dynamic analysis of moisture stress in tall fescue (festuca arundinacea) using canopy temperature, irradaition, and vapor deficit. Trans. ASAE 43, 101-109.

Allen, R., Pereira, L.S., Raes, D., Smith, M., 1998. FAO Irrigation and Drainage Paper No. 56, FAO. < https://doi.org/10.1016/j.eja.2010.12.001>.

Ben-Gal, A., Agam, N., Alchanatis, V., Cohen, Y., Yermiyahu, U., Zipori, I., Presnov, E., Sprintsin, M., Dag, A., 2009. Evaluating water stress in irrigated olives: correlation of soil water status, tree water status, and thermal imagery. Irrig. Sci. 27, 367-376. https://doi.org/10.1007/s00271-009-0150-7.

Boonen, C., Joniaux, O., Janssens, K., Berckmans, D., Lemeur, R., Kharoubi, A., Pien, H., 2000. Modeling dynamic behavior of leaf temperature at three-dimensional positions to step variations in air temperature and light. Trans. ASAE-Am. Soc. Agric. Eng. 43, 1755-1766. https://doi.org/10.13031/2013.3078.

Cannavo, P., Bouhoun Ali, H., Chantoiseau, E., Migeon, C., Charpentier, S., Bournet, P.E., 2016. Stomatal resistance of New Guinea Impatiens pot plants. Part 2: model extension for water restriction and application to irrigation scheduling. Biosyst. Eng. 149, 82-93. https://doi.org/10.1016/j.biosystemseng.2016.07.001.

Chai, T., Draxler, R.R., 2014. Root mean square error (RMSE) or mean absolute error (MAE)? -Arguments against avoiding RMSE in the literature. Geosci. Model Dev. 7, 1247-1250. https://doi.org/10.5194/gmd-7-1247-2014.

Delgoda, D., Malano, H., Saleem, S.K., Halgamuge, M.N., 2016. Irrigation control based on model predictive control (MPC): formulation of theory and validation using weather forecast data and AQUACROP model. Environ. Model. Softw. 78, 40-53. https://doi.org/10.1016/j.envsoft.2015.12.012.

Desta, T.Z., Van Brecht, a., Meyers, J., Baelmans, M., Berckmans, D., 2004. Combining CFD and data-based mechanistic (DBM) modelling approaches. Energy Build. 36, 535-542. https://doi.org/10.1016/j.enbuild.2003.12.015.

Dhillon, R., Udompetaikul, V., Rojo, F., Slaughter, D., 2014. Detection of plant water stress using leaf temperature and microclimatic measurements in almond, walnut, and grape crops. Trans. ASABE 297-304. https://doi.org/10.13031/trans.57.10319.

Fuentes, S., De Bei, R., Pech, P., Tyerman, S., 2012. Computational water stress indices obtained from thermal image analysis of grapevine canopies. Irrig. Sci. 30.

González-Dugo, M.P., Moran, M.S., Mateos, L., Bryant, R., 2006. Canopy temperature variability as an indicator of crop water stress severity. Irrig. Sci. 24, 233-240. https://doi.org/10.1007/s00271-005-0022-8.

González, M.G., Ramos, T.B., Carlesso, R., Paredes, P., Petry, M.T., Martins, J.D., Aires, N.P., Pereira, L.S., 2015. Modelling soil water dynamics of full and deficit drip irrigated maize cultivated under a rain shelter. Biosyst. Eng. 132, 1-18. https://doi.org/ 10.1016/j.biosystemseng.2015.02.001.

Grant, O.M., Tronina, L., Jones, H.G., Chaves, M.M., 2007. Exploring thermal imaging variables for the detection of stress responses in grapevine under different irrigation regimes. J. Exp. Bot. 58, 815-825. https://doi.org/10.1093/jxb/erl153.

Hedley, C.B., Knox, J.W., Raine, S.R., Smith, R., 2014. Water: advanced irrigation technologies. Encycl. Agric. Food Syst. 5, 378-406. https://doi.org/https://doi.org/10. 1016/B978-0-444-52512-3.00087-5.

Idso, S.B., Jackson, R.D., Pinter, P.J., Reginato, R.J., Hatfield, J.L., 1981. Normalizing the stress-degree-day parameter for environmental variability. Agric. Meteorol. 24, 45-55. https://doi.org/10.1016/0002-1571(81)90032-7.

Jackson, R.D., Idso, S.B., Reginato, R.J., Pinter, P.J., 1981. Canopy temperature as a crop water stress indicator. Water Resour. Res. https://doi.org/10.1029/ WR017i004p01133.

Jones, H.G., 2014. Plants and Microclimate, third ed. Cambridge University Press, New York.

Jones, H.G., 1999. Use of infrared thermometry for estimation of stomatal conductance as a possible aid to irrigation scheduling. Agric. For. Meteorol. 95, 139-149. https://doi. org/10.1016/S0168-1923(99)00030-1.

Jones, H.G., Aikman, D., McBurney, T.A., 1997. Improvements to infra-red thermometry 
for irrigation scheduling in humid climates. Acta Hortic.

Jones, H.G., Leinonen, I., 2003. Thermal imaging for the study of plant water relations. J. Agric. Meteorol. 59, 205-217. https://doi.org/10.2480/agrmet.59.205.

Jones, H.G., Schofield, P., 2008. Thermal and other remote sensing of plant stress. Gen. Appl. Plant Physiol. 34, 19-32.

King, B.A., Shellie, K.C., 2016. Evaluation of neural network modeling to predict nonwater-stressed leaf temperature in wine grape for calculation of crop water stress index. Agric. Water Manage. 167, 38-52. https://doi.org/10.1016/j.agwat.2015.12. 009.

Kirchsteiger, H., Pölzer, S., Johansson, R., Renard, E., del Re, L., 2011. Direct continuous time system identification of MISO transfer function models applied to type 1 diabetes. IEEE Conf. Decis. Control Eur. Control Conf. pp. 5176-5181. < https://doi. org/10.1109/CDC.2011.6161344>.

Kuscu, H., Turhan, A., Demir, A.O., 2014. The response of processing tomato to deficit irrigation at various phenological stages in a sub-humid environment. Agric. Water Manage. 133, 92-103. https://doi.org/10.1016/j.agwat.2013.11.008.

Lozoya, C., Mendoza, C., Aguilar, A., Román, A., Castelló, R., 2016. Sensor-based model driven control strategy for precision irrigation. J. Sensors 2016.

Maes, W.H., Steppe, K., 2012. Estimating evapotranspiration and drought stress with ground-based thermal remote sensing in agriculture: a review. J. Exp. Bot. 63, 695-709. https://doi.org/10.1093/jxb/err313.

Möller, M., Alchanatis, V., Cohen, Y., Meron, M., Tsipris, J., Naor, A., Ostrovsky, V., Sprintsin, M., Cohen, S., 2007. Use of thermal and visible imagery for estimating crop water status of irrigated grapevine. J. Exp. Bot. 58, 827-838. https://doi.org/10. 1093/jxb/erl115.

Monaghan, J.M., Daccache, A., Vickers, L.H., Hess, T.M., Weatherhead, E.K., Grove, I.G., Knox, J.W., 2013. More "crop per drop": constraints and opportunities for precision irrigation in European agriculture. J. Sci. Food Agric. 93, 977-980. https://doi.org/ 10.1002/jsfa.6051.

Monaghan, J.M., Vickers, L.H., Grove, I.G., Beacham, A.M., 2017. Deficit irrigation reduces postharvest rib pinking in wholehead Iceberg lettuce, but at the expense of head fresh weight. J. Sci. Food Agric. 97, 1524-1528. https://doi.org/10.1002/jsfa. 7895.

Oh, M., Carey, E.E., Rajashekar, C.B., 2010. Regulated water deficits improve phytochemical concentration in lettuce. J. Am. Soc. Hortic. Sci. 135, 223-229.

Osroosh, Y., Troy Peters, R., Campbell, C.S., Zhang, Q., 2015. Automatic irrigation scheduling of apple trees using theoretical crop water stress index with an innovative dynamic threshold. Comput. Electron. Agric. 118, 193-203. https://doi.org/10. 1016/j.compag.2015.09.006.

Payero, J.O., Irmak, S., 2006. Variable upper and lower crop water stress index baselines for corn and soybean. Irrig. Sci. 25, 21-32. https://doi.org/10.1007/s00271-0060031-2.
Qiu, G.Y., Omasa, K., Sase, S., 2009. An infrared-based coefficient to screen plant environmental stress: concept, test and applications. Funct. Plant Biol. 36, 990-997. https://doi.org/10.1071/FP09132.

Quanten, S., De Valck, E., Cluydts, R., Aerts, J.M., Berckmans, D., 2006. Individualized and time-variant model for the functional link between thermoregulation and sleep onset. J. Sleep Res. 15, 183-198. https://doi.org/10.1111/j.1365-2869.2006. 00519.x.

Rojo, F., Kizer, E., Upadhyaya, S., Ozmen, S., Ko-Madden, C., Zhang, Q., 2016. A leaf monitoring system for continuous measurement of plant water status to assist in precision irrigation in grape and almond crops. IFAC-PapersOnLine 49, 209-215. https://doi.org/10.1016/j.ifacol.2016.10.039.

Shao, G.C., Zhang, Z.Y., Liu, N., Yu, S.E., Xing, W.G., 2008. Comparative effects of deficit irrigation (DI) and partial rootzone drying (PRD) on soil water distribution, water use, growth and yield in greenhouse grown hot pepper. Sci. Hortic. (Amsterdam) 119, 11-16. https://doi.org/10.1016/j.scienta.2008.07.001.

Shaughnessy, S.A., Evett, S.R., Colaizzi, P.D., Howell, T.A., 2012. A crop water stress index and time threshold for automatic irrigation scheduling of grain sorghum. Agric. Water Manage. 107, 122-132. https://doi.org/10.1016/j.agwat.2012.01.018.

Story, D., Kacira, M., 2015. Design and implementation of a computer vision-guided greenhouse crop diagnostics system. Mach. Vis. Appl. 26, 495-506. https://doi.org/ 10.1007/s00138-015-0670-5.

Tanner, C., 1963. Plant temperatures. Agron. J. 55, 210-211.

Taylor, C.J., Pedregal, D.J., Young, P.C., Tych, W., 2007. Environmental time series analysis and forecasting with the Captain toolbox. Environ. Model. Softw. 22, 797-814. https://doi.org/10.1016/j.envsoft.2006.03.002.

Thom, A.S., Oliver, H.R., 1977. On Penman's equation for estimating regional evaporation. Quaterly J. R. Meteorol. Soc. 103, 345-357.

Weber, N., Zupanc, V., Jakopic, J., Veberic, R., Mikulic-Petkovsek, M., Stampar, F., 2016. Influence of deficit irrigation on strawberry (Fragaria $x$ ananassa Duch.) fruit quality. J. Sci. Food Agric. https://doi.org/10.1002/jsfa.7806.

Young, P.C., 2006. The data-based mechanistic approach to the modelling, forecasting and control of environmental systems. Annu. Rev. Control 30, 169-182. https://doi. org/10.1016/j.arcontrol.2006.05.002.

Young, P.C., Garnier, H., 2006. Identification and estimation of continuous-time, databased mechanistic (DBM) models for environmental systems. Environ. Model. Softw. 21, 1055-1072. https://doi.org/10.1016/j.envsoft.2005.05.007.

Youssef, A., Yen, H.H., Özcan, S.E., Berckmans, D., 2011. Data-based mechanistic modelling of indoor temperature distributions based on energy input. Energy Build. 43, 2965-2972. https://doi.org/10.1016/j.enbuild.2011.06.042.

Yuan, G., Luo, Y., Sun, X., Tang, D., 2004. Evaluation of a crop water stress index for detecting water stress in winter wheat in the North China Plain. Agric. Water Manage. 64, 29-40. https://doi.org/10.1016/S0378-3774(03)00193-8. 